Atmospheric Environment, Volume 41, Issue 13, April 2007, Pages 2870-2880.

\title{
Appropriateness of selecting different averaging times for modelling chronic and acute exposure to environmental odours
}

G.H. Drew ${ }^{1}$, R. Smith ${ }^{1}$, V. Gerard ${ }^{1}$, C. Burge ${ }^{1}$, M. Lowe ${ }^{1,2}$, R. Kinnersley ${ }^{3}$, R. Sneath ${ }^{4}$, and

\author{
P.J. Longhurst ${ }^{1 *}$ \\ ${ }^{1}$ Integrated Waste Management Centre, Sustainable Systems Department, School of Applied \\ Sciences, Cranfield University, Cranfield, Bedfordshire, MK43 0AL, UK. \\ ${ }^{2}$ Waste Recycling Group, 900 Pavilion Drive, Northampton Business Park, Northampton, \\ NN4 7RG, UK \\ ${ }^{3}$ Air Science Team, Environment Agency, Olton Court, 10 Warwick Road, Olton, Solihull B92 \\ $7 H X, U K$ \\ ${ }^{4}$ Silsoe Odours Ltd, Wrest Park, Silsoe, MK45 4HS, UK
}

\begin{abstract}
Odour emissions are episodic, characterised by periods of high emission rates, interspersed with periods of low emissions. It is frequently the short term, high concentration peaks that result in annoyance in the surrounding population. Dispersion modelling is accepted as a useful tool for odour impact assessment, and two approaches can be adopted. The first approach of modelling the hourly average concentration can underestimate total odour concentration peaks, resulting in annoyance and complaints. The second modelling approach involves the use of short averaging times. This study assesses the appropriateness of using different averaging times to model the dispersion of odour from a landfill site. We also examine perception of odour in the community in conjunction with the modelled odour
\end{abstract}

* corresponding author Email address:

p.j.longhurst@cranfield.ac.uk(P.J. Longhurst); tel: +44 (0)1234 754953; fax: +44 (0)1234 751671 
Drew G.H., Smith R., Gerard V., Burge C., Lowe M., Kinnersley R., Sneath R. and Longhurst P.J. (2007). Appropriateness of selecting different averaging times for modelling chronic and acute exposure to environmental odours. Atmospheric Environment, 41, (13), 2870-2880.

dispersal, by using community monitors to record incidents of odour. The results show that with the shorter averaging times, the modelled pattern of dispersal reflects the pattern of observed odour incidents recorded in the community monitoring database, with the modelled odour dispersing further in a north easterly direction. Therefore, the current regulatory method of dispersion modelling, using hourly averaging times, is less successful at capturing peak concentrations, and does not capture the pattern of odour emission as indicated by the community monitoring database. The use of short averaging times is therefore of greater value in predicting the likely nuisance impact of an odour source and in framing appropriate regulatory controls.

Keywords: Odour, annoyance, dispersion modelling, averaging times 
Drew G.H., Smith R., Gerard V., Burge C., Lowe M., Kinnersley R., Sneath R. and Longhurst P.J. (2007). Appropriateness of selecting different averaging times for modelling chronic and acute exposure to environmental odours. Atmospheric Environment, 41, (13), 2870-2880.

\section{Introduction}

\subsection{Background}

The emission of odour from landfill sites and industrial processes is a recurrent problem for operators and regulators, who have to deal with complaints from the public. Population growth and housing needs have resulted in increasing numbers living within close proximity to these odour sources. In the UK, $80 \%$ of the population live within $2 \mathrm{~km}$ of either a closed or active landfill site (Elliott et al, 2001) and therefore, the potential for exposure to odours is high. Odour at landfill sites is primarily caused by the anaerobic decomposition of biodegradable waste. The exact nature of odour emissions is therefore dependent on waste characteristics, such as composition and age.

Gostelow et al (2004) describe the sequence of events leading to odour annoyance as: formation of the odour at source; emission from source; transport to receptor; and perception by receptor, who then makes a judgement as to whether the odour causes an annoyance or not.

Transport of the odour is affected by factors such as the season, time of day and the atmospheric conditions influencing dispersion of the odour (e.g. turbulence, wind speed and wind direction). Detectability and annoyance potential will influence the response by receptors. Perception of odour may therefore be affected by the combination of odorous compounds released during formation (Sarkar et al, 2003a), as well as the characteristics of the odour itself, such as duration and frequency of emission.

Odour intensity and hedonic (the pleasantness or unpleasantness of the odour) properties experienced by the population may be interpreted as strong or offensive, respectively, in 
Drew G.H., Smith R., Gerard V., Burge C., Lowe M., Kinnersley R., Sneath R. and Longhurst P.J. (2007). Appropriateness of selecting different averaging times for modelling chronic and acute exposure to environmental odours. Atmospheric Environment, 41, (13), 2870-2880.

place of faint or not-unpleasant. Miedema et al (2000) show that the hedonic tone or pleasantness of the odour has an affect on the annoyance people feel. Both et al (2004) demonstrate how hedonic tone has a clear impact on the annoyance felt by receptors at low concentrations, with pleasant odours having significantly lower annoyance potential than neutral or unpleasant odours. The hedonic tone of unpleasant odours at higher concentrations does not affect the annoyance potential of these odours, and Both et al (2004) show that odour frequency is sufficient to predict odour annoyance from unpleasant odours.

Factors including personal health, social status and previous exposure to odours may all influence how a person perceives an odour (Cavalini et al, 1991; Winneke and Neuf, 1992). A person's response to odour can further be influenced by the context of exposure, such as the presence of other odours and the reactions of people around them. Some members of the population are more predisposed to complain, while others may adopt alternative coping strategies. If the odour is perceived to be associated with a potential health risk, the probability of concern and increased annoyance is higher (Dalton, 2003).

The primary concern during monitoring and measuring odours is determining the threshold at which an odour becomes a nuisance. Two terms used to define the response of the public to odour emissions are annoyance and nuisance. Annoyance is defined by Lindvall and Radford (1973) as the negative response associated with exposure to an agent or event that is believed to cause harm to the individual, and thus requires a coping strategy. A nuisance is commonly defined in law as the threshold at which a population experiences annoyance (van Harreveld, 2001), from repeated incidents of exposure. These may be translated into law as a statutory limit. 
Drew G.H., Smith R., Gerard V., Burge C., Lowe M., Kinnersley R., Sneath R. and Longhurst P.J. (2007). Appropriateness of selecting different averaging times for modelling chronic and acute exposure to environmental odours. Atmospheric Environment, 41, (13), 2870-2880.

\subsection{Odour regulation}

The difficulty in predicting perception and response to odour at different concentrations is problematic for the definition of emission limits with which to regulate industries causing odour. Two metrics are commonly used to define annoyance, the sensory metric of odour concentration or 'dose' to which a receptor is predicted to be exposed, and the time or duration of exposure (Clarkson, 2000).

Mahin et al (2000) reviews standards for various USA state authorities, as well as European and Pacific Rim countries. Their review shows wide variations as to what is considered acceptable across these authorities. The pattern that emerges from studying odour regulations across the world (Table 1) is that less densely populated countries, such as Australia and the USA, have more stringent regulations than more densely population countries. The logic behind such stringent regulations is that if there is no odour, there will be no complaints and therefore no problem (Schulz and van Harreveld, 1996). However, stringent limits such as these can result in high remedial costs to the process operators. Most European countries seek to regulate less stringently by providing quantitative limits aimed at reducing annoyance to an acceptable level at an acceptable cost.

No regulations are imposed by the European Union with respect to odours, except for a standard for the measurement of odours, developed by the European standardisation committee (CEN, 1995; 2003), and a draft standard exists sewage treatment works (Table 1). Individual countries within Europe have made significant advances in the regulation of odours, particularly the Netherlands (see Table 1) and Germany. German government Guidelines on odour in ambient air (GOAA, 1999) set out requirements for monitoring odours and maximum emission limits in terms of odour hours. In practice, the concentration 
Drew G.H., Smith R., Gerard V., Burge C., Lowe M., Kinnersley R., Sneath R. and Longhurst P.J. (2007). Appropriateness of selecting different averaging times for modelling chronic and acute exposure to environmental odours. Atmospheric Environment, 41, (13), 2870-2880.

fluctuations may be estimated by simply scaling the hourly mean by a factor of ten

(Christensen et al, 1996). The preferred method for assessment of initial odour impacts is the sampling regime described in the guidelines. Any additional odour impacts may be assessed using dispersion modelling.

Within the UK, odour from existing facilities is primarily controlled by the Environmental Protection Act of 1990. The current de facto level for preventing odour complaints is set at below 5 ou $\mathrm{m}^{-3}$ for $98 \%$ of the year, based on research in The Netherlands (Clarkson, 2000). The water industry has also proposed a two tier system for new and existing wastewater treatment plants (UKWIR, 2004)

\subsection{Odour assessment}

Odour emissions are episodic, characterised by periods of high emission rates, interspersed with periods of low emissions. The human olfactory sense responds within seconds to a stimulus. Odours therefore create a response in the receptor quicker than most other atmospheric pollutants (Irish Environmental Protection Agency, 2001). Greater annoyance is caused by more short periods of odour than by longer lasting odour emissions, as the olfactory sense is able to adapt to persistent odours, thereby reducing annoyance (GOAA, 1999). However, the short term, high peak concentrations may still be detected and considered an annoyance (Miedema et al, 2000). In other words, it is frequently the fluctuations from the mean concentration, and not the actual mean itself, that determine how the odour is perceived (Best et al, 2001). However, odour regulations are currently expressed as hourly average concentrations. 
Drew G.H., Smith R., Gerard V., Burge C., Lowe M., Kinnersley R., Sneath R. and Longhurst P.J. (2007). Appropriateness of selecting different averaging times for modelling chronic and acute exposure to environmental odours. Atmospheric Environment, 41, (13), 2870-2880.

Dispersion modelling has frequently been used to assess the potential dispersion of odour from industrial sources (Sheridan et al, 2004). Two approaches to modelling odour nuisance for regulation can be adopted. The first option aims to model the "real life" situation and is an attempt to model and understand the odour concentrations that may cause annoyance, or in other words, the concentration average over a certain time period, usually one hour. This is the approach often used by regulators and is acceptable as long as exposure is not underestimated and a "tolerable level” is defined.

The use of concentrations averaged over such periods effectively filters out peak and short term fluctuations, resulting in conservative results with respect to maximum concentration levels (Sarkar et al, 2003b). While a single peak may not result in annoyance, repeated high peaks at times of high exposure could be missed by using averages. Simms et al (2000) considered it unlikely that an odour will be a nuisance until it is detectable for longer periods of time, typically longer than three minutes.

The second modelling approach involves the use of short averaging times. In this way, it is possible to capture concentration peaks, and thereby obtain a more accurate prediction of odour dispersion. New generation air dispersion models can be run at averaging times of less than an hour, although they are typically not used for short interval averaging times by regulators. Furthermore, the most frequently available atmospheric input data for these dispersion models are hourly averaged variables.

Any model will require simplifying assumptions to be made and will have built-in uncertainties, uncertainty being a measure of the reliability that can be associated with the results of a model (Yegnan et al, 2002). In particular, uncertainties associated with source 
Drew G.H., Smith R., Gerard V., Burge C., Lowe M., Kinnersley R., Sneath R. and Longhurst P.J. (2007). Appropriateness of selecting different averaging times for modelling chronic and acute exposure to environmental odours. Atmospheric Environment, 41, (13), 2870-2880.

term measurements, for example, instrument failure or incomplete data recording, will be carried over into modelling studies. If the magnitudes of measured results are considered as a Gaussian distribution, the "tails" of the distribution, representing relatively low sample numbers, are associated with a higher margin of statistical error (Ballesta, 2005; Irish Environmental Protection Agency, 2001). Furthermore, odours are commonly the results of a release of several odorous compounds, but they are generally modelled as a single indicator compound, usually with a low odour threshold and a high emission rate. Taken with the regulatory approach of modelling the hourly average concentration, this can mean that total odour concentration peaks could be seriously underestimated, resulting in annoyance and complaints.

The exploration and quantification of uncertainties aids in defining sampling methods in future studies, and in refining and validating model options. It is therefore vital for the model to be tested and validated, not to eliminate the uncertainties, but to understand and quantify them.

\subsection{Study rationale}

Odour concentration measurements within a laboratory alone, using olfactometry, or instrumental analysis, fail to capture the properties of the odour as perceived by a community as it does not capture the other characteristics of the odour such as hedonic tone, which influence the way the odour is perceived by the public. Hedonic tone assessments can also be carried out in the laboratory. Sarkar et al (2003b) analysed the link between odour dispersion and the perception of odour from a landfill site, using data from a monitoring programme within a community. The response of the community was found to vary greatly. 
Drew G.H., Smith R., Gerard V., Burge C., Lowe M., Kinnersley R., Sneath R. and Longhurst P.J. (2007). Appropriateness of selecting different averaging times for modelling chronic and acute exposure to environmental odours. Atmospheric Environment, 41, (13), 2870-2880.

Odour emissions are episodic, and it is the infrequent, high concentration peaks that cause annoyance. Dispersion modelling is accepted as a useful tool for odour impact assessment and guidance exists for odour dispersion modelling (e.g. Environment Agency, 2002). However, little attention has been paid to the appropriate definition of averaging time when attempting to understand off-site amenity impacts

This study attempts to assess the appropriateness of using different averaging times to model the dispersion of odour from a landfill site. These results will be compared with a community monitoring programme database. We aim to examine the perception of the odour in the community in conjunction with the modelled odour dispersal.

\section{Material and methods}

The landfill site studied, located in Bedfordshire, is licensed to receive up to 600 waste vehicles a day, although it usually accepts about half that number. These vehicles contain commercial, household and industrial waste. This site has been studied for approximately 10 years by researchers at Cranfield University.

\subsection{Community monitoring}

In order to determine if annoyance was being caused by the landfill site, two indications of odour annoyance were used:

i. Complaints to the operators from all members of the community;

ii. Daily monitoring records made by selected members of the local community.

Site inspections carried out by the Community Liaison Officer from the company are used to understand the causes of incidents and assess the control the operator has over these incidents. 
Drew G.H., Smith R., Gerard V., Burge C., Lowe M., Kinnersley R., Sneath R. and Longhurst P.J. (2007). Appropriateness of selecting different averaging times for modelling chronic and acute exposure to environmental odours. Atmospheric Environment, 41, (13), 2870-2880.

Complaints to the landfill operators can be made through a number of routes, either directly to the site, to the operator's Community Liaison Officer, to the local authority (County Council), to Environmental Health Officers (EHOs), or to the Environment Agency, which incorporates the previous Waste Regulation Authority. Each of these parties ensure that the operator and local authority are informed of the complaint. The details of the complaints include the location, name (where given) of complainant, number of people complaining, the nature of the problem, the time the odour occurred, the time of reporting, result of the investigation as to the cause, and the weather conditions recorded from the automatic weather station on-site. The most common recorded complaints are from the following sources:

i. Landfill gas emissions caused by methanogenesis taking place within the landfill cell.

ii. The construction of liquid waste disposal trenches, which expose existing waste deposits prior to appropriate covering.

iii. Refuse recently delivered to the landfill site and not yet placed within the cell structure.

iv. Odours arising from certain types of waste (e.g. chemical treatment waste or malodorous waste) as it is delivered.

In addition to the complaints data, a system of odour monitoring by selected members of the surrounding community has been established since 1994. These daily reports record all odour types, coded into four categories: Local odours (e.g. bonfires), landfill odours, odour from a neighbouring brick-works and agricultural odours. Community monitors have all volunteered to take part in the study and are anonymous to the landfill operators. In addition to their monitoring role are encouraged to report complaints to the operators as any other member of the community would normally do. 
Drew G.H., Smith R., Gerard V., Burge C., Lowe M., Kinnersley R., Sneath R. and Longhurst P.J. (2007). Appropriateness of selecting different averaging times for modelling chronic and acute exposure to environmental odours. Atmospheric Environment, 41, (13), 2870-2880.

The number of monitors has varied throughout the period of the study, from 13 to 25, with 43 individuals contributing since 1994. An average of 17 monitors have recorded odours within the area during the ten years of the study. Each person monitoring is given guidance in the procedures and tested for specific anosmia (lack of sensitivity) to the mercaptan family of odours. This data is of help in interpreting the significance of the complaint data. In addition to describing the odour, monitors are asked to quantify the scale and offensiveness of the odour, the time of monitoring, and general weather conditions. The monitors are trained to assess the likely cause of the odour and record the certainty of the assessments as part of the process. By comparing the timing and location of complaints with the recorded incidents, an indication as to the extent to which complaints reflect the recorded experience of landfill odours can be found. In addition, the monitoring and complaints data provide real life evidence of where odour occurs and where annoyance results.

\subsection{Dispersion modelling}

\subsubsection{Odour sampling}

Odour samples were taken from three locations within the landfill site on a single afternoon in July 1998 (UK summer), representing the active cell, the operational area and freshly tipped waste. The sampling location within each of these areas was chosen at random. Samples were collected using a Lindvall hood for waste surfaces at approximately every 10 minutes between 14:00 and 16:00 (Gostelow et al., 2003). Samples were collected using the "lung principle”, where the sampling bag (Nalophan-NA) is placed in a rigid container under pressure, which causes the bag to fill with a volume of sample equal to that which has been removed from the container using a vacumn pump. Two samples were taken from each area. The samples were assessed (within 30 hours) using dynamic dilution olfactometry, at the 
Drew G.H., Smith R., Gerard V., Burge C., Lowe M., Kinnersley R., Sneath R. and Longhurst P.J. (2007). Appropriateness of selecting different averaging times for modelling chronic and acute exposure to environmental odours. Atmospheric Environment, 41, (13), 2870-2880.

Silsoe Research Institute (SRI), following the protocols described in the then draft CEN standard (CEN, 1995). An “Olfaktomat” dynamic dilution olfactometer (Project Research, Amsterdam) was used with a panel of four or more members. The panel members all had a personal threshold of between 20ppb and 80ppb to the reference gas (n-butanol). A minimum of three dilutions at ascending concentrations were presented to the panel.

\subsubsection{Model experimental design}

A series of model runs were undertaken to examine the effects of changing the averaging times using the ADMS 3.1 air dispersion model (Carruthers et al, 1994; CERC, 2003). ADMS is a new generation, advanced steady state, Gaussian-like dispersion model. ADMS is capable of modelling continuous plumes, short duration releases and complex terrain. The model simulates point, line, area and volume sources, and can calculate the pollution or odour concentration at a number of user defined receptors. The model has been shown to perform in a comparable manner to similar new generation models (Hanna et al, 2000). The model is widely used in the UK by consultants as well as regulatory and government bodies.

The ADMS model was run with topographical and meteorological data for September 1997 to October 1998. This time period was chosen to represent the full cycle of seasons, centred around the date of the odour sampling (in July 1998). The averaging times chosen for the five experiments were 60 seconds, 15 minutes, 30 minutes, 45 minutes and 1 hour.

The freshly tipped waste and operational areas were modelled as single area sources. Both sources were represented as a point source with a diameter of $70 \mathrm{~m}$. Although this does not accurately reflect the size and shape of these sources on the ground, this was the closest possible fit that could be modelled. The velocity used for the freshly tipped waste area was 
Drew G.H., Smith R., Gerard V., Burge C., Lowe M., Kinnersley R., Sneath R. and Longhurst P.J. (2007). Appropriateness of selecting different averaging times for modelling chronic and acute exposure to environmental odours. Atmospheric Environment, 41, (13), 2870-2880.

$0.018 \mathrm{~m} / \mathrm{s}$, whereas for the operational area, the velocity used was $0.019 \mathrm{~m} / \mathrm{s}$, based on the outlet air volume flowrate from the Lindvall Hood during sampling. The spatial dimensions of the active cell were represented by three separate area sources, chosen to closely represent the actual dimensions of the source, each with a diameter of $100 \mathrm{~m}$ and a velocity of 0.018 $\mathrm{m} / \mathrm{s}$, again based on the outlet air volume flowrate from the Lindvall Hood during sampling. The emission rate for the active cell was divided equally between the three area sources.

\section{Results and discussion}

\subsection{Community monitoring}

The map in Figure 1 shows the location of the monitors in relation to the landfill site. The size of the circle locating each monitor gives an indication of the number of recorded incidents of landfill odour at each location. From this map, it is obvious that the most frequent occurrences of landfill odour occur to the north east of the site. The wind-rose for the site (Figure 2) shows that the predominant wind direction is from the southwest, which would support the observation from the community monitoring data that most of the recorded incidents occur to the north east of the site.

During the study period (September 1997 to October 1998) only six separate odour incidents were complained about, although the operator received more than one complaint regarding three of the events. On further examination, one of these incidents was found to be related to a local industry that produce an odour similar to the tanker trenches on a landfill site. The majority of the complaints were made by residents of the nearby village, located to the north of the site. 
Drew G.H., Smith R., Gerard V., Burge C., Lowe M., Kinnersley R., Sneath R. and Longhurst P.J. (2007). Appropriateness of selecting different averaging times for modelling chronic and acute exposure to environmental odours. Atmospheric Environment, 41, (13), 2870-2880.

\subsection{Dispersion modelling}

\subsubsection{Odour emissions}

From each of the measured concentrations, an emission rate based on the outlet air volume was calculated. These were converted to an emission rate for each of the areas (Table 2). The geometric mean of the two samples from each area was used for atmospheric dispersion modelling. The variance in the emission rates between the samples at each area was 1.78 (fresh waste), 3.19 (operational area) and 0.15 (active cell).

Karnik and Parry (2001) measured odour from waste deposition in the range of $60 \mathrm{ou} / \mathrm{m}^{2} / \mathrm{s}$. More recently, Sironi et al (2005) measured a concentration of $59 \mathrm{ou}_{\mathrm{E}} / \mathrm{m}^{2} / \mathrm{s}$ from freshly tipped waste, and Nicolas et al (2005) measured a maximum concentration of $30 \mathrm{ou}_{\mathrm{E}} / \mathrm{m}^{2} / \mathrm{s}$ from a landfill site. The measurements by Karnik and Parry (2001) and Sironi et al (2005) were taken by direct sampling, whereas the measurements by Nicolas et al (2006) are based on a sniffing panel, which may explain the difference. In light of these published concentrations, the odour concentrations measured at this study site are considered to be low and to represent a best case scenario. The areas were chosen for sampling at random and had low quantities of putrescible material on the surface, which may explain the low odour concentrations measured. In order to examine the worst case scenario, the measured concentrations were multiplied by ten to reflect the published concentrations.

\subsubsection{Model experiments}

The results show that with the shorter averaging times, the modelled $99^{\text {th }}$ percentile concentration is higher, and the odour disperses further (Figure 3). Table 3 shows the maximum concentrations for each of the averaging times. The maximum $99^{\text {th }}$ percentile concentration under the shortest averaging time (1 minute) is approximately $1.2 \mathrm{ou} / \mathrm{m}^{3}$ (for 
Drew G.H., Smith R., Gerard V., Burge C., Lowe M., Kinnersley R., Sneath R. and Longhurst P.J. (2007). Appropriateness of selecting different averaging times for modelling chronic and acute exposure to environmental odours. Atmospheric Environment, 41, (13), 2870-2880.

the measurements we do not us $\mathrm{ou}_{\mathrm{E}} / \mathrm{m}^{3}$ because the method was not the official European standard EN13725 at that time, only the draft CEN standard) higher than for the longest averaging time (1hour).

The modelled pattern of dispersal reflects the pattern of observed odour incidents recorded in the community monitoring database, with the modelled odour dispersing further in a north easterly direction (Figure 3). In order to compare the modelled and observed results more closely, 6 of the monitors were selected for further analysis. Their location in relation to the landfill site is shown in Figure 4. The graph in Figure 5 shows the $99^{\text {th }}$ percentile concentration for each of these monitors, for the different averaging times. All the results show that the longer the averaging time, the lower the concentration. For example, a $99^{\text {th }}$ percentile concentration of $1.09 \mathrm{ou} / \mathrm{m}^{3}$ is predicted with a 1 hour averaging time. This concentration increases to $2.27 \mathrm{ou} / \mathrm{m}^{3}$ with a 1 minute averaging time. This represents a twofold increase in the concentration. Mussio et al (2001) use $2 \mathrm{ou} / \mathrm{m}^{3}$ as a level where odour is readily detectable at a receptor. Monitor 1 has reported incidents of landfill odour $17.2 \%$ of the time during the study year, suggesting that this monitor is exposed to concentrations above $2 \mathrm{ou} / \mathrm{m}^{3}$ on a number of occasions. The only modelled concentration that reflects this is that predicted with the shortest averaging time of 1 minute. This pattern holds for monitors 26, 27 and 34. Monitor 14 is the most distant from the source of all the monitors, and so the modelled concentrations are considerably lower and do not reach the $2 \mathrm{ou} / \mathrm{m}^{3}$ threshold.

Monitor 35 is the closest to the source, and recorded incidents of landfill odour $19.2 \%$ of the days in a year. The modelled concentrations at this location are also the highest for all the monitors. With an averaging time of 1 hour, the $99^{\text {th }}$ percentile concentration at this location is $2.23 \mathrm{ou} / \mathrm{m}^{3}$, rising to $4.02 \mathrm{ou} / \mathrm{m}^{3}$ with a 1 minute averaging time. 
Drew G.H., Smith R., Gerard V., Burge C., Lowe M., Kinnersley R., Sneath R. and Longhurst P.J. (2007). Appropriateness of selecting different averaging times for modelling chronic and acute exposure to environmental odours. Atmospheric Environment, 41, (13), 2870-2880.

The ratio of modelled frequencies to observed frequencies exceedences of $2 \mathrm{ou} / \mathrm{m}^{3}$ is a useful indicator of how well the model predicts the observed odour frequency (Mussio et al, 2001). The closer the values are to 1, the more accurate the model prediction. The graph (Figure 6) shows this ratio plotted against the observed frequency of exceedences of $2 \mathrm{ou} / \mathrm{m}^{3}$ for the 1 hour, 15 minute and 1 minute averaging times for the six monitors. All the values for the shorter ( 1 and 15 minutes) averaging times are closer to the ideal value of 1 , suggesting that the shorter averaging times provide a better prediction of the observed odour incidents than the longer (1 hour) averaging time.

\section{Conclusions}

This study has examined the influence of different averaging times on modelled odour dispersion from a landfill site. These modelled results were compared with a community monitoring database that reports incidents of odour detected in the areas surrounding the landfill site. We have shown that the current regulatory method of dispersion modelling, using hourly averaging times, is less successful at capturing peak concentrations, and does not capture the pattern of odour emission as indicated by the community monitoring database. The use of short averaging times produces a modelled pattern of dispersal that more closely matches the observed database. This approach is therefore of greater value in predicting the likely nuisance impact of an odour source and in framing appropriate regulatory controls.

\section{Acknowledgements}

GHD is an Environment Agency supported Postdoctoral Fellow. We acknowledge the technical support of the Waste Recycling Group. The opinions expressed are those of the authors’ alone. 
Drew G.H., Smith R., Gerard V., Burge C., Lowe M., Kinnersley R., Sneath R. and Longhurst P.J. (2007). Appropriateness of selecting different averaging times for modelling chronic and acute exposure to environmental odours. Atmospheric Environment, 41, (13), 2870-2880. 
Drew G.H., Smith R., Gerard V., Burge C., Lowe M., Kinnersley R., Sneath R. and Longhurst P.J. (2007). Appropriateness of selecting different averaging times for modelling chronic and acute exposure to environmental odours. Atmospheric Environment, 41, (13), 2870-2880.

\section{References}

Ballesta P.P., 2005. The uncertainty of averaging a time series of measurements and its use in environmental legislation. Atmospheric Environment, 39, 2003-2009.

Best, P.R., Lunney, K.E., and Killip, C.A., 2001. Statistical elements of predicting the impact of a variety of odour sources. Water Science and Technology, 44(9), 157-164.

Both, R., Sucker, K., Winneke, G., and Koch, E., 2004. Odour intensity and hedonic tone important parameters to describe odour annoyance to residents? Water Science and Technology, 50(4), 83-92.

Carruthers, D.J., Holroyd, R.J., Hunt, J.C.R., Weng, W.S., Robins, A.G., Apsley, D.D., Thompson, D.J. and Smith, F.B., 1994. UK-ADMS: A new approach to modelling dispersion in the earth's atmospheric boundary layer. Wind Engineering and Industrial Aerodynamics, 52,139-153.

Cavalini, P.M., Koeter-Kemmering, L.G., and Pulles, M.P.J., 1991. Coping with odour annoyance and odour concentrations: three field studies. Journal of Environmental Psychology, 11, 123-142.

CEN, 1995. Odour concentration measurement by dynamic dilution olfactometry.

CEN/TC264wg2 Odours. CEN Kommission Reinhaltung der Luft, im VDI und DIN, Postfach 1011 39, 40002, Dusseldorf, Germany.

CEN, 2003. Air quality - Determination of odour concentration by dynamic olfactometry. CEN EN 13725: 2003.

CERC, 2003. ADMS 3 Technical Specification. Cambridge Environmental Research Consultants.

Christensen, T.H., Cossu, R., and Stegmann, R., 1996. Landfilling of waste: Biogas. Spon, London, ISBN 0419194002. 
Drew G.H., Smith R., Gerard V., Burge C., Lowe M., Kinnersley R., Sneath R. and Longhurst P.J. (2007). Appropriateness of selecting different averaging times for modelling chronic and acute exposure to environmental odours. Atmospheric Environment, 41, (13), 2870-2880.

Clarkson, C., 2000. Smells and planning: the use of olfactometry in planning. Wastes Management, August, Institute of Waste Management, UK.

Dalton, P., 2003. Review: Upper airway irritation, odor perception and health risk due to airborne chemicals. Toxicology Letters, 140-141, 239-248.

Elliott, P., Morris, S., Briggs, D., de Hoogh, C., Hurt, C., Kold Jensen, T., Maitland, I., Lewin, A., Richardson, S., Jon Wakefeld, J., and Jarup, L., 2001. Birth outcomes and selected cancers in populations living near landfill sites. Report to the Department of Health, UK.

Environment Agency (2002) Integrated Pollution Prevention and Control (IPPC) Draft Horizontal Guidance for Odour Part 1 - Regulation and Permitting. Environment Agency, Bristol.

GOAA, 1999. Guideline on odour in ambient air - Determination and Assessment of Odour in Ambient Air (1994). (Feststellung und Beurteilung von Geruchsimmissionen Geruchsimmiions-Richtlinie) Länderausschuss für Immissionsschutz, LAISchriftenreihe No. 5, Berlin; revised version 1999 (available in English). Available online at http://www.lua.nrw.de/luft/gerueche/infos.htm.

Gostelow, P., Parsons, S.A., and Lovell, M., 2004. Integrated odour modelling for sewage treatment works. Water Science and Technology, 50 (4), 169-176.

Gostelow, P., Longhurst, P.J., Parsons, S.A., and Stuetz, R.M., 2003. Sampling for Measurement of Odours. IWA Publishing, London, UK, ISBN 1843390337.

Hanna, S.R., Egan, B.A., Purdum, J., and Wagler, J., 2000. Evaluation of the ADMS, AERMOD and ISC3 dispersion models with the Optex, Duke Forest, Kincaid, Indianapolis, and Lovett field data sets. International Journal of Environment and Pollution, 16(1-6), 301-314. 
Drew G.H., Smith R., Gerard V., Burge C., Lowe M., Kinnersley R., Sneath R. and Longhurst P.J. (2007). Appropriateness of selecting different averaging times for modelling chronic and acute exposure to environmental odours. Atmospheric Environment, 41, (13), 2870-2880.

Irish Environmental Protection Agency, 2001. Odour impacts and odour emission control measures for intensive agriculture. R\&D Report Series No. 14, OdourNet UK Ltd, Bath.

Karnik, M., and Parry, C., 2001. Landfill odour control. A practitioner’s experience. In Christensen, T.H., Cossu, R., and Stegmann, R., eds. Leachate and Landfill Gas. Sardinia 2001, Eighth International Waste Management and Landfill Symposiums Proceedings, Volume II, 691-700.

Lindvall, T., and Radford, T.P., 1973. Measurements of annoyance due to exposure to environmental factors. Environmental Research, 6, 1-36.

McGahan, E., Nicholas, P., and Watts, P., 2002. Nuisance criteria for impact Assessment. Application of emission rate data in modelling and assessment. Paper 5877/22. 13 November 2002. Available online at http://www.fsaconsulting.net/pdfs/Nuisance\%20Criteria\%20Paper.PDF.

Mahin, T., Pope, R., and McGinley, C., 2000. When is a smell a nuisance? An overview of different approaches taken around the world in setting odor-control regulations. Water Environment \& Technology, 12(5), 49-53.

McIntyre, A., 2000. Application of dispersion modelling to odour assessment: a practical tool or a complex trap? Water Science and Technology, 41(6), 81-88.

Miedema, H.M.E., Walpot, J.I., Vos, H., and Steunenberg, C.F., 2000. Exposure-annoyance relationships for odour from industrial sources. Atmospheric Environment, 34, $2927-$ 2936.

Mussio, P., Gnyp, A.W., and Henshaw, P.F., 2001. A fluctuating plume dispersion model for the prediction of odour-impact frequencies from continuous stationary sources. Atmospheric Environment, 35, 2955-2962. 
Drew G.H., Smith R., Gerard V., Burge C., Lowe M., Kinnersley R., Sneath R. and Longhurst P.J. (2007). Appropriateness of selecting different averaging times for modelling chronic and acute exposure to environmental odours. Atmospheric Environment, 41, (13), 2870-2880.

Nicolas, J., Craffe, F., and Romain, A.C., 2005. Estimation of odor emission rate from landfill areas using the sniffing team method. Waste Management, in press.

Sarkar, U., Hobbs, S.E., and Longhurst, P., 2003a. Dispersion of odour: a case study with a municipal solid waste landfill site in North London, United Kingdom. Journal of Environmental Management, 68(2), 153-160.

Sarkar, U., Longhurst, P., and Hobbs, S.E., 2003b. Community modelling: a tool for correlating estimates of exposure with perception of odour from municipal solid waste (MSW) landfills. Journal of Environmental Management, 68(2), 133-140.

Schulz, T.J., and van Harreveld, A.P., 1996. International moves towards standardisation of odour measurement using olfactometry. Water Science and Technology, 34 (3-4), 541-547.

Sheridan, B.A., Hayes, E.T., Curran, T.P., and Dodd, V.A., 2004. A dispersion modelling approach to determining the odour impact of intensive pig production units in Ireland. Bioresource Technology, 91, 145-152.

Sironi, S., Capelli, L., Céntola, P., Del Rosso, R., and Il Grande, M., 2005. Odour emission factors for assessment and prediction of Italian MSW landfills odour impact. Atmospheric Environment, 39, 5387-5394.

UKWIR, 2004. Odour Standards for the Wastewater Industry. UK Water Industry Research Report 04/WW/13/6, ISBN: 1-84057-341-4.

Van Harreveld, A.P., 2001. From odorant formation to odour nuisance: new definitions for discussing a complex process. Water Science and Technology, 44 (9), 9-15.

Winneke, G., and Neuf, M., 1992. Psychological responses to sensory stimulation by environmental stressors: trait or stait? Applied Psychology: An International Review, 41(3), 257-267. 
Drew G.H., Smith R., Gerard V., Burge C., Lowe M., Kinnersley R., Sneath R. and Longhurst P.J. (2007). Appropriateness of selecting different averaging times for modelling chronic and acute exposure to environmental odours. Atmospheric Environment, 41, (13), 2870-2880.

Yegnan, A., Williamson, D.G., and Graettinger, A.J., 2002. Uncertainty analysis in air dispersion modelling. Environmental Modelling and Software, 17, 639-649. 
Drew G.H., Smith R., Gerard V., Burge C., Lowe M., Kinnersley R., Sneath R. and Longhurst P.J. (2007). Appropriateness of selecting different averaging times for modelling chronic and acute exposure to environmental odours. Atmospheric Environment, 41, (13), 2870-2880.

\section{Figure Captions}

Fig. 1 The location of community odour monitors within the study area, in relation to the landfill site. The size of the circles gives an indication of the number of recorded incidents of landfill odour at each location during the period from September 1997 to October 1998.

Fig. 2 Windrose for the study area based on wind data for the period September 1997 to October 1998.

Fig.3 The ground level odour concentration for five different averaging times: a) 1 minute; b) 15 minutes; c) 30 minutes; d) 45 minutes; and e) 1 hour.

Fig. 4 The locations of the selected monitors in relation to the landfill site.

Fig. 5 The $99^{\text {th }}$ percentile concentrations for the selected monitors, for each of the modelled averaging times.

Fig. 6 The ratio of modelled to observed frequencies for an odour concentration of $2 \mathrm{ou}_{\mathrm{E}} / \mathrm{m}$.

\section{Table Captions}

Table 1: Odour standards and regulations for selected countries.

Table 2: Odour concentrations and emission rates for the three regions within the landfill site.

Table 3: Modelled odour concentrations for each of the five averaging times. 
Drew G.H., Smith R., Gerard V., Burge C., Lowe M., Kinnersley R., Sneath R. and Longhurst P.J. (2007). Appropriateness of selecting different averaging times for modelling chronic and acute exposure to environmental odours. Atmospheric Environment, 41, (13), 2870-2880. 
Drew G.H., Smith R., Gerard V., Burge C., Lowe M., Kinnersley R., Sneath R. and Longhurst P.J. (2007). Appropriateness of selecting different averaging times for modelling chronic and acute exposure to environmental odours. Atmospheric Environment, 41, (13), 2870-2880.

\section{TABLES}

Table 1: Odour standards and regulations for selected countries.

\begin{tabular}{|c|c|c|}
\hline Country & Odour standards & Reference \\
\hline Australia & $\begin{array}{l}\text { Odour assessed at receptor (except in Victoria } \\
\text { where assessment is at the property boundary). } \\
\text { Odour concentrations and percentiles vary for } \\
\text { each state }\end{array}$ & $\begin{array}{l}\text { McGahan et al. } \\
\text { (2002) }\end{array}$ \\
\hline USA & No odour should be detected at site boundary & $\begin{array}{l}\text { Schulz and van } \\
\text { Harreveld (1996) }\end{array}$ \\
\hline $\begin{array}{l}\text { European Union } \\
\text { (draft for sewage } \\
\text { treatment works) }\end{array}$ & $\begin{array}{l}\text { Zero odour at site boundary or residential area; or } \\
\text { less than } 1 \mathrm{ou} / \mathrm{m}^{3} \text { for more than } 98 \% \text { of the time }\end{array}$ & CEN (1995; 2003) \\
\hline Netherlands & $\begin{array}{l}1 \mathrm{ou} / \mathrm{m}^{3} \text { for } 2 \% \text { of the time at the nearest } \\
\text { residential buildings for existing facilities }\end{array}$ & Mahin et al (2000) \\
\hline & $\begin{array}{l}\text { For new facilities, time decreases to } 0.5 \% \\
\text { Odour concentration may increase to } 5 \mathrm{ou} / \mathrm{m}^{3} \text { for } \\
\text { large area sources }\end{array}$ & McIntyre (2000) \\
\hline Germany & $\begin{array}{l}\text { Residential and mixed areas: } 0.10 \text { odour hours } \\
\text { Industrial and commercial areas } 0.15 \text { odour hours }\end{array}$ & GOAA (1999) \\
\hline UK & $\begin{array}{l}5 \mathrm{ou} / \mathrm{m}^{3} \text { for } 98 \% \text { of the year (de facto level) } \\
5 \mathrm{ou} / \mathrm{m}^{3} \text { as a } 98^{\text {th }} \text { percentile for new-build } \\
\text { wastewater treatment plants } \\
10 \mathrm{ou} / \mathrm{m}^{3} \text { as a } 98^{\text {th }} \text { percentile for existing } \\
\text { wastewater treatment plants }\end{array}$ & $\begin{array}{l}\text { Clarkson (2000) } \\
\text { UKWIR (2004) }\end{array}$ \\
\hline Denmark & Should not exceed $5-10 \mathrm{ou} / \mathrm{m}^{3} 99 \%$ of the time & Mahin et al (2000) \\
\hline Japan & $\begin{array}{l}\text { Uses a } 0-5 \text { odour-intensity scale, with } 0 \text { being no } \\
\text { odour and } 5 \text { being repulsive. Odour is acceptable } \\
\text { at } 2.5-3.5 \text { on this scale. }\end{array}$ & Mahin et al (2000) \\
\hline
\end{tabular}

Table 2: Odour concentrations and emission rates for the three regions within the landfill site.

\begin{tabular}{lcccc}
\hline Region & $\begin{array}{c}\text { Odour concentration } \\
\left(\mathrm{ou} / \mathrm{m}^{3}\right)\end{array}$ & $\begin{array}{c}\text { Mean outlet emission } \\
\text { rate }\left(\mathrm{ou} / \mathrm{m}^{2} / \mathrm{s}\right)^{\mathrm{a}}\end{array}$ & Area (m) & $\begin{array}{c}\text { Area emission } \\
\text { rate }(\mathrm{ou} / \mathrm{s})\end{array}$ \\
\hline $\begin{array}{l}\text { Freshly } \\
\text { tipped waste }\end{array}$ & 399 & 3.17 & $70 \times 20$ & 4438 \\
$\begin{array}{l}\text { Operational } \\
\text { area }\end{array}$ & 176 & 5.50 & $70 \times 80$ & 30800 \\
Active cell & 301 & 2.19 & $200 \times 300$ & 131400 \\
& 76.5 & & & \\
\hline
\end{tabular}

${ }^{a}$ Geometric mean of the emissions rates based on outlet air volume for the two samples taken at each area

Table 3: Modelled odour concentrations for each of the five averaging times.

\begin{tabular}{|c|c|c|c|}
\hline Averaging time & Annual average & Maximum (at $99^{\text {th }}$ percentile) & Maximum (at $98^{\text {th }}$ percentile) \\
\hline 1 minute & 1.08516 & 14.5149 & 12.6157 \\
\hline 15 minutes & 1.08257 & 14.1593 & 12.4141 \\
\hline 30 minutes & 1.08017 & 13.8758 & 12.2128 \\
\hline 45 minutes & 1.0779 & 13.6348 & 12.0319 \\
\hline 60 minutes & 1.07557 & 13.3932 & 11.8656 \\
\hline
\end{tabular}


Drew G.H., Smith R., Gerard V., Burge C., Lowe M., Kinnersley R., Sneath R. and Longhurst P.J. (2007). Appropriateness of selecting different averaging times for modelling chronic and acute exposure to environmental odours. Atmospheric Environment, 41, (13), 2870-2880. 
Drew G.H., Smith R., Gerard V., Burge C., Lowe M., Kinnersley R., Sneath R. and Longhurst P.J. (2007). Appropriateness of selecting different averaging times for modelling chronic and acute exposure to environmental odours. Atmospheric Environment, 41, (13), 2870-2880.

\section{FIGURES}

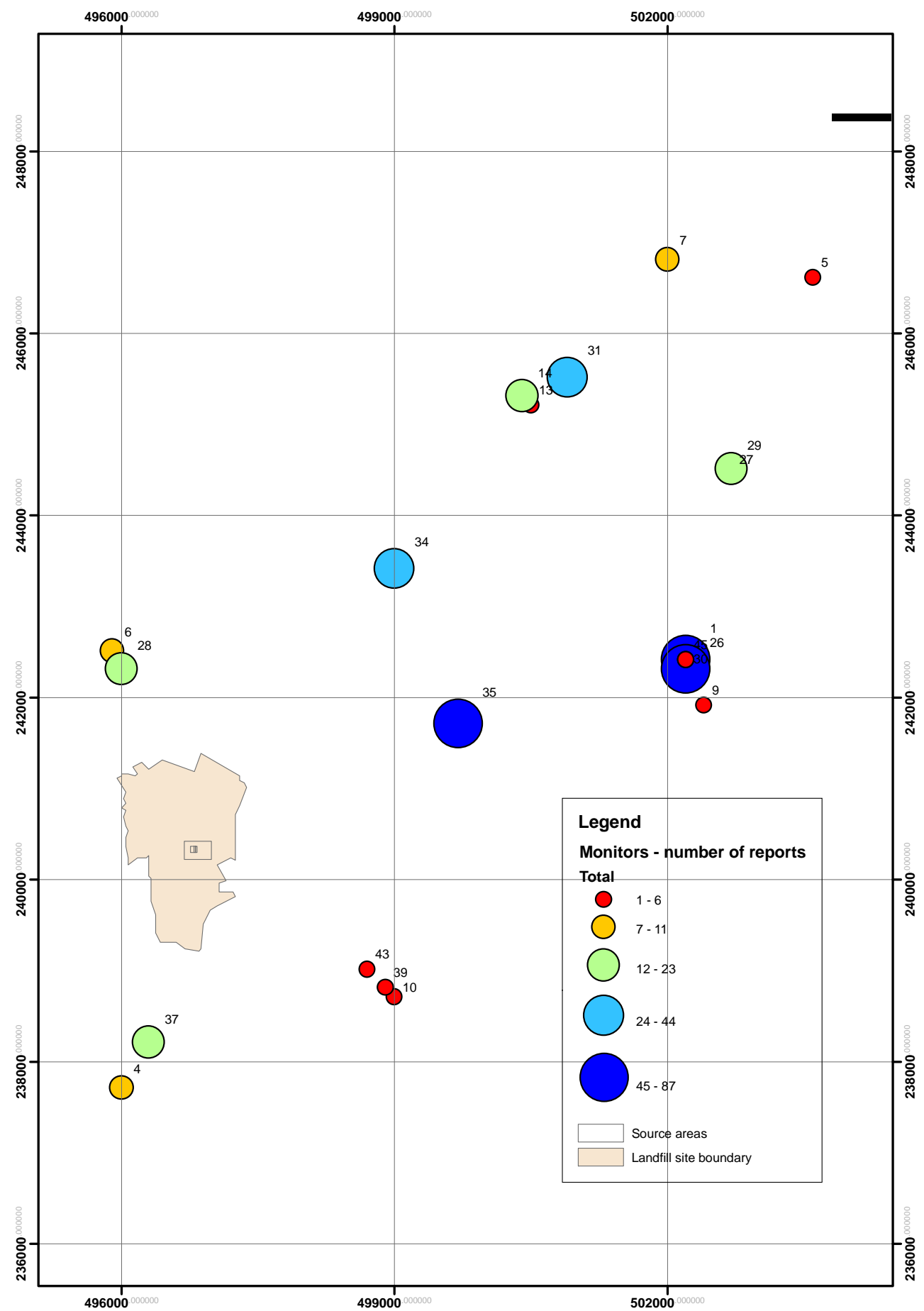


Drew G.H., Smith R., Gerard V., Burge C., Lowe M., Kinnersley R., Sneath R. and Longhurst P.J. (2007). Appropriateness of selecting different averaging times for modelling chronic and acute exposure to environmental odours. Atmospheric Environment, 41, (13), 2870-2880.

Fig. 1 The location of community odour monitors within the study area, in relation to the landfill site. The size of the circles gives an indication of the number of recorded incidents of landfill odour at each location during the period from September 1997 to October 1998.

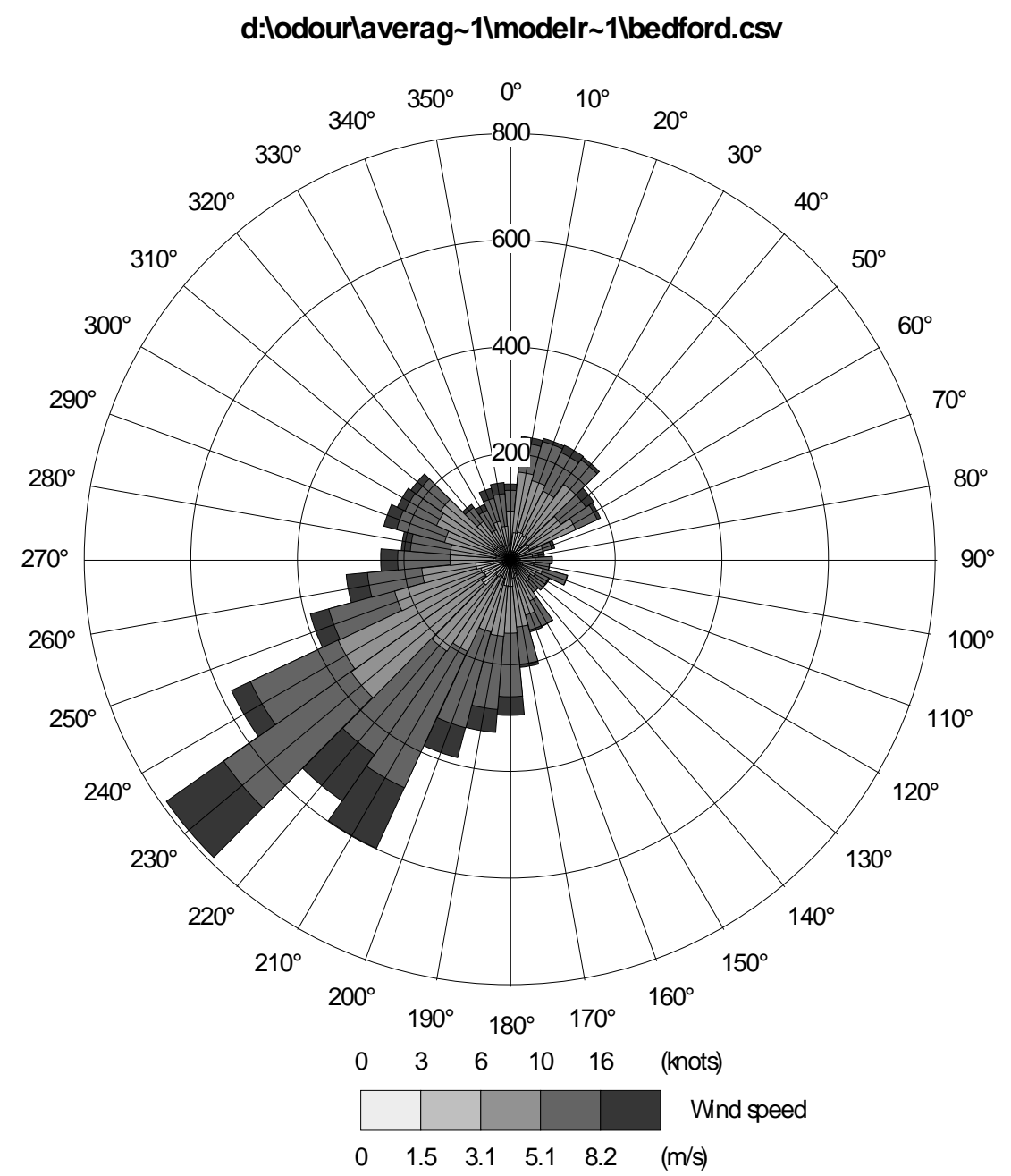

Fig. 2 Windrose for the study area based on wind data for the period September 1997 to October 1998. 
Drew G.H., Smith R., Gerard V., Burge C., Lowe M., Kinnersley R., Sneath R. and Longhurst P.J. (2007). Appropriateness of selecting different averaging times for modelling chronic and acute exposure to environmental odours. Atmospheric Environment, 41, (13), 2870-2880.
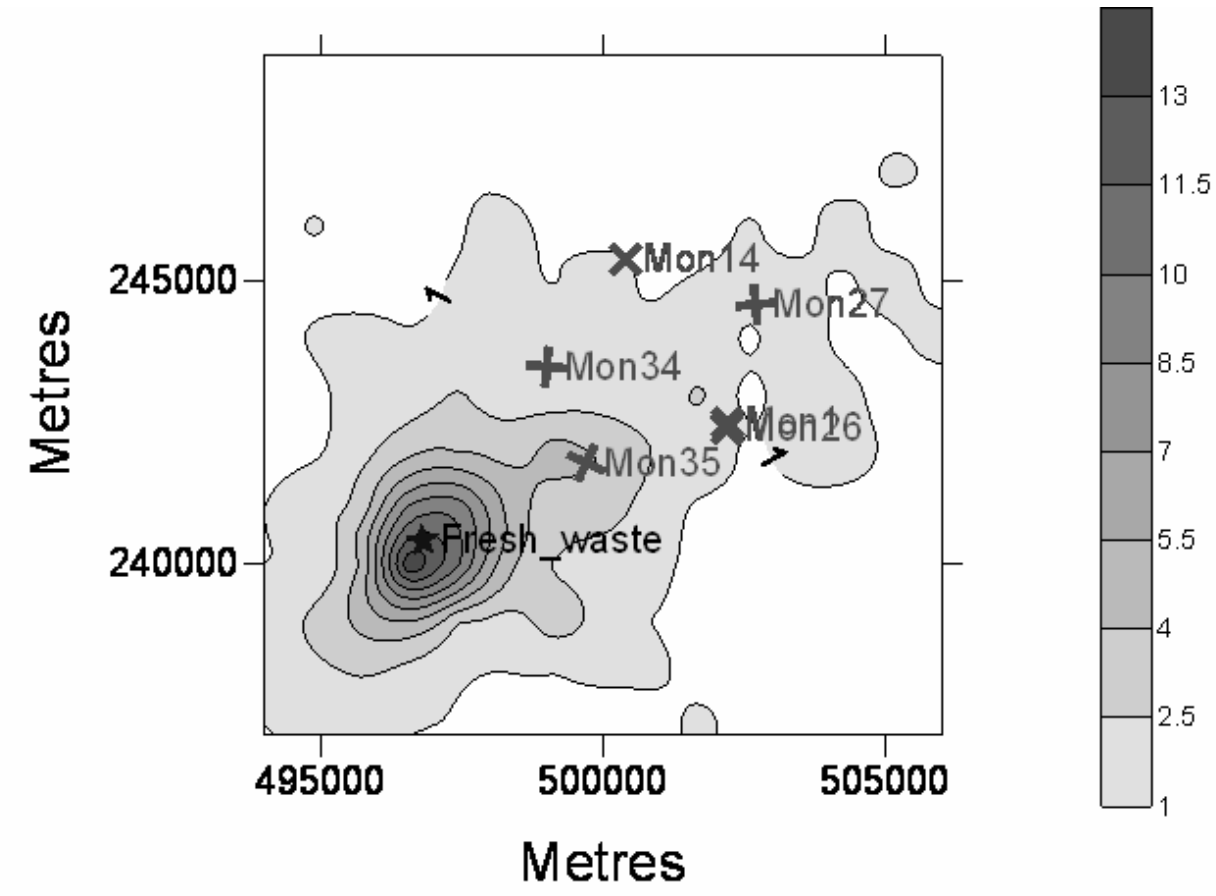

a) 
Drew G.H., Smith R., Gerard V., Burge C., Lowe M., Kinnersley R., Sneath R. and Longhurst P.J. (2007). Appropriateness of selecting different averaging times for modelling chronic and acute exposure to environmental odours. Atmospheric Environment, 41, (13), 2870-2880.

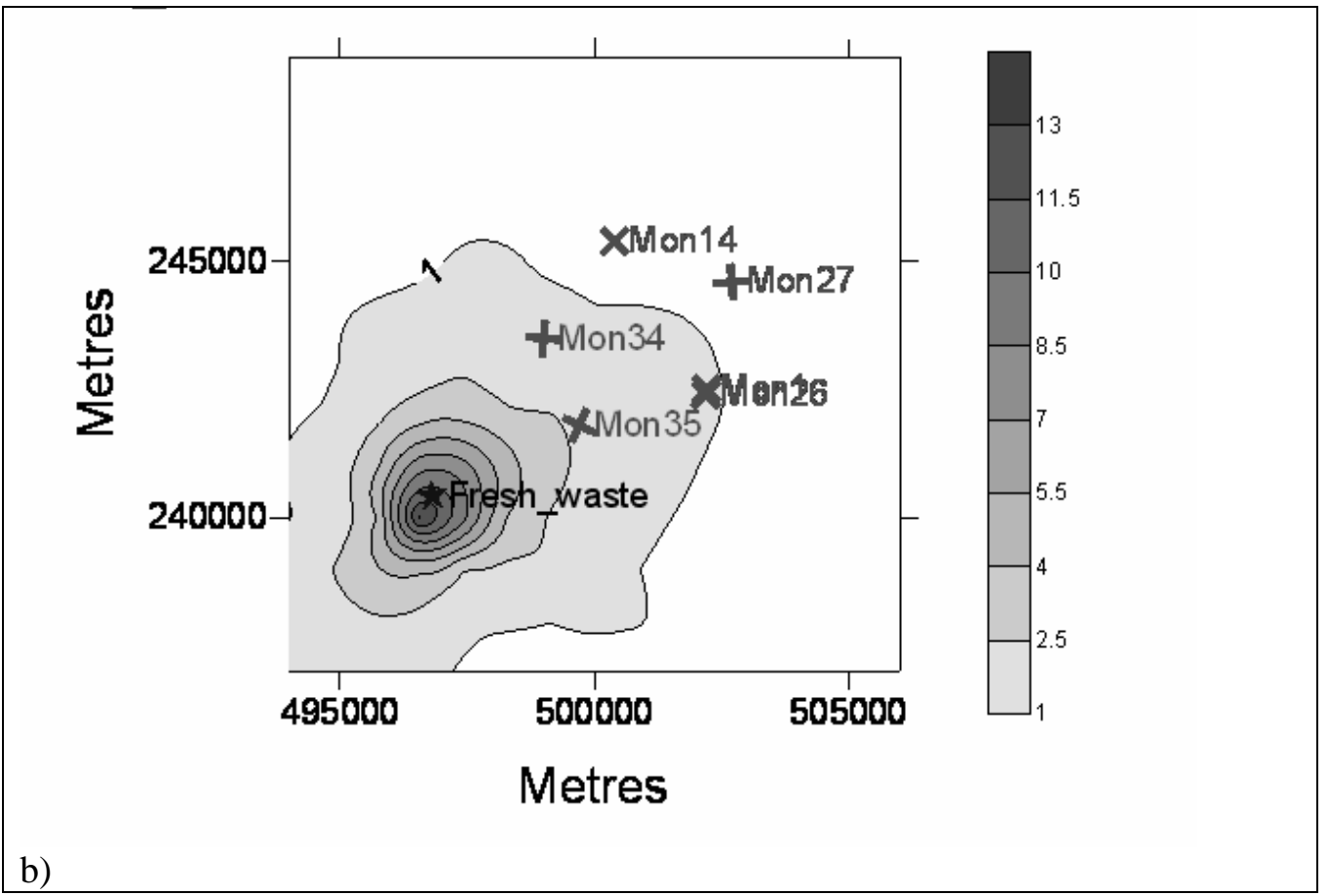

Fig.3. The ground level odour concentration for five different averaging times: a) 1 minute; and b) 1 hour. 
Drew G.H., Smith R., Gerard V., Burge C., Lowe M., Kinnersley R., Sneath R. and Longhurst P.J. (2007). Appropriateness of selecting different averaging times for modelling chronic and acute exposure to environmental odours. Atmospheric Environment, 41, (13), 2870-2880.

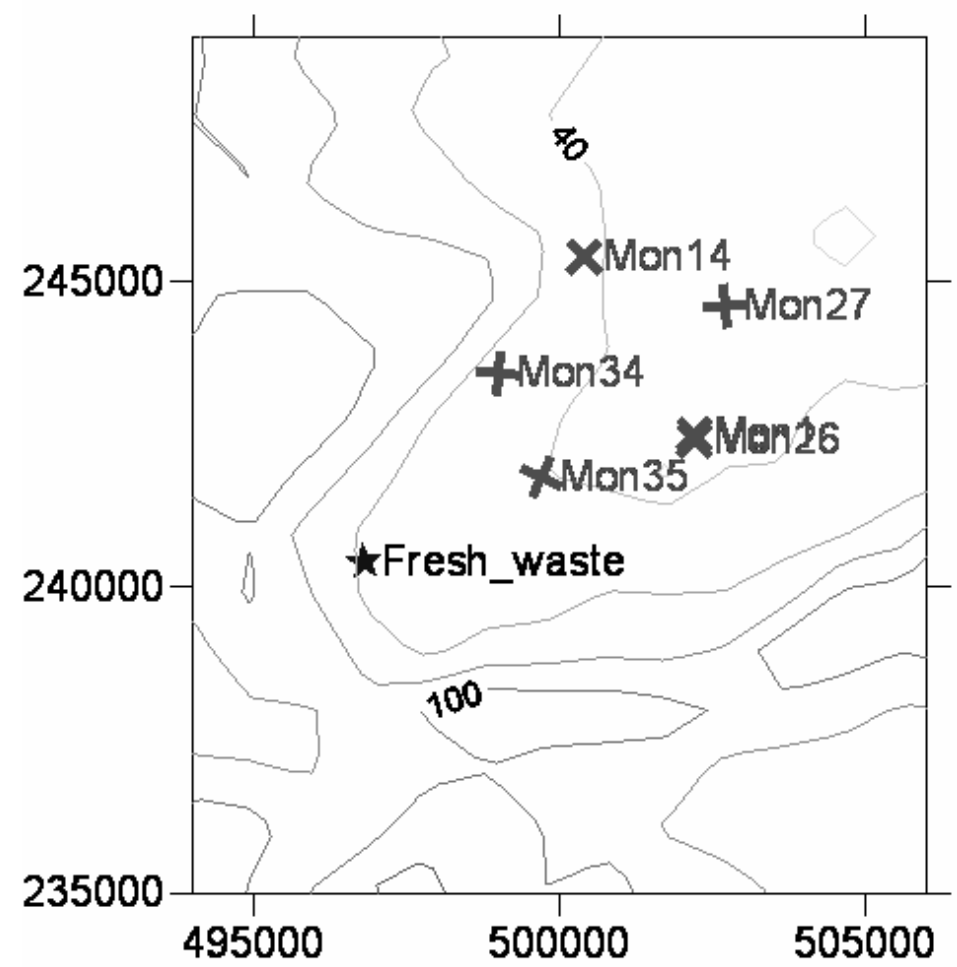

Fig. 4. The locations of the selected monitors in relation to the landfill site, with the contours showing the topography of the area. 
Drew G.H., Smith R., Gerard V., Burge C., Lowe M., Kinnersley R., Sneath R. and Longhurst P.J. (2007). Appropriateness of selecting different averaging times for modelling chronic and acute exposure to environmental odours. Atmospheric Environment, 41, (13), 2870-2880.

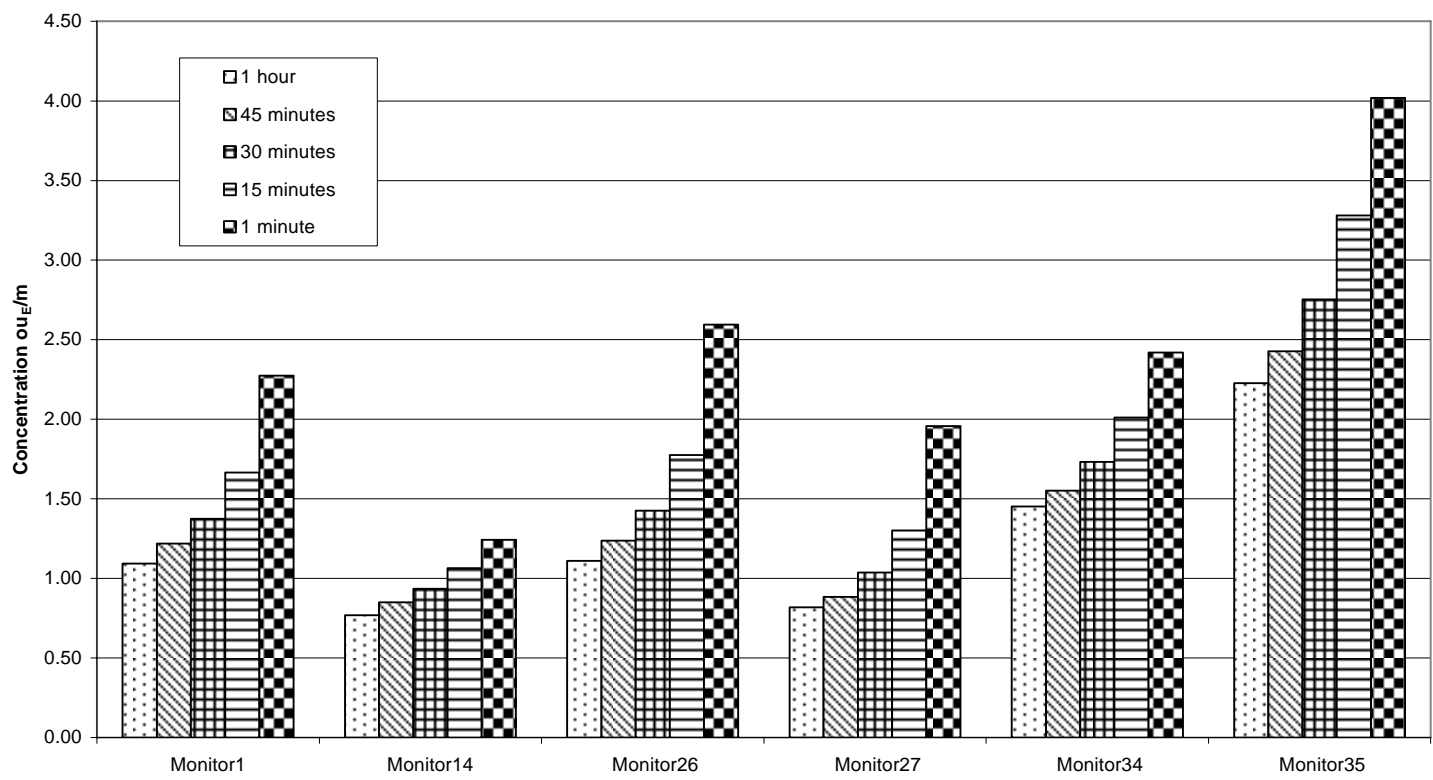

Fig. 5 The $99^{\text {th }}$ percentile concentrations for the selected monitors, for each of the modelled averaging times.

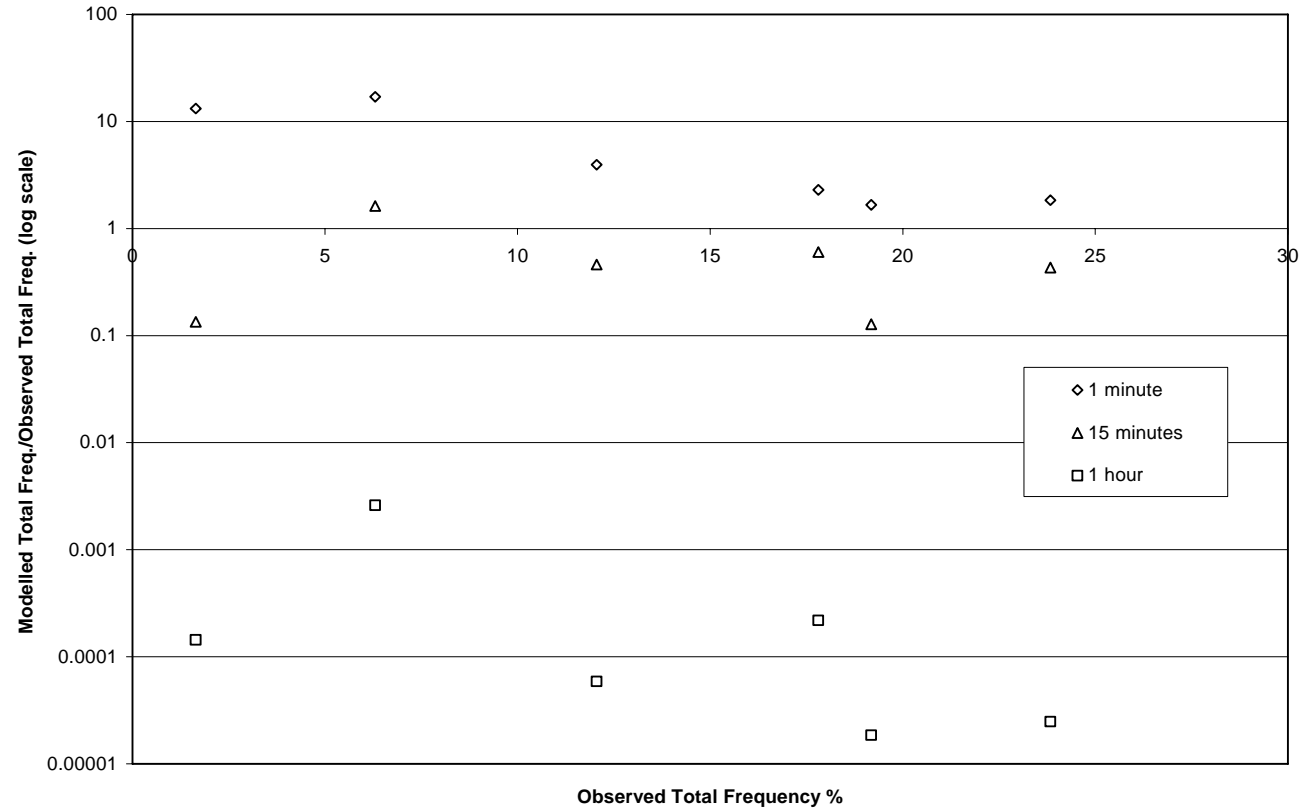

Fig. 6 The ratio of modelled to observed frequencies for an odour concentration of $2 \mathrm{ou}_{\mathrm{E}} / \mathrm{m}^{3}$. 